\title{
ÍNDICE DE DESENVOLVIMENTO DA EDUCAÇÃO BÁSICA E EFICÁCIA ESCOLAR: EVIDÊNCIAS DE UMA PESQUISA COMPARATIVA \\ http://dx.doi.org/10.5902/2318133842610
}

\author{
Pollyanna Silva de Paulo Faria ${ }^{1}$ \\ Maria Teresa Gonzaga Alves ${ }^{2}$
}

\begin{abstract}
Resumo
Neste artigo apresenta-se resultados de pesquisa pela qual se investigou características de escolas que podem incidir no aprendizagem dos alunos. Por meio de uma análise correlacional entre os dados do Índice de Desenvolvimento da Educação Básica - Ideb - e o indicador de nível socioeconômico das escolas, foram identificadas três escolas localizadas na mesma região de Belo Horizonte/MG, da mesma rede de ensino, mas que apresentaram resultados diferenciados em termos de eficácia escolar. Foram analisados dados secundários e primários obtidos por meio de observação e entrevistas realizadas com diretores, supervisores e professores em três categorias principais: liderança, acompanhamento pedagógico e práticas escolares. Os resultados mostraram que a atuação dos profissionais, engajados nos processos de ensino e aprendizagem, são relevantes para a eficácia escolar.

Palavras-chave: avaliação educacional; eficácia escolar; liderança escolar; acompanhamento pedagógico; práticas escolares.
\end{abstract}

\section{DEVELOPMENT INDEX OF BASIC EDUCATION AND SCHOOL EFFECTIVENESS: EVIDENCES OF A COMPARATIVE RESEARCH}

\begin{abstract}
In this article we present results from a research which investigated school characteristics that can interfere in students' learning. Through a correlational analysis between the data from the Basic Education Development Index and the index of school socioeconomic level, we have identified three schools located in the region of Belo Horizonte/MG, Brazil, from the same educational system, but that have different results regarding school effectiveness. We analyzed secondary and primary data from observation and interviews with principals, supervisors, and teachers on three main categories: leadership, pedagogical follow-up, and school practices. The results have shown that the work of professionals, who are engaged in the learning-teaching processes, is relevant for school effectiveness.
\end{abstract}

Key-words: educational assessment; school effectiveness; school leadership; pedagogical monitoring; school practices.

\footnotetext{
${ }^{1}$ Fundação de Desenvolvimento Gerencial, Brasil. E-mail: pollydot@gmail.com.

2 Universidade Federal de Minas Gerais, Brasil. E-mail: mtga@ufmg.br.

\begin{tabular}{|l|l|l|l|l|l|} 
Regae: Rev. Gest. Aval. Educ. & Santa Maria & v. 9 & n. 18 & Pub. contínua 2020 & p. 1-20
\end{tabular}
} 


\section{Introdução}

esde a introdução do Índice de Desenvolvimento da Educação Básica - Ideb - na política educacional, uma escola pública de Belo Horizonte/MG, localizada num bairro distante da área central da cidade, ganhou manchetes em jornais, inclusive na imprensa internacional pelo alto valor do seu Ideb $^{3}$.

O conceito de qualidade em educação é polissêmico (Cury, 2010; Gusmão, 2013; Oliveira; Araújo, 2005). O uso do Ideb como indicador desse atributo tem méritos, mas também limitações (Soares; Xavier, 2013). O Ideb foi criado no âmbito do Plano de Desenvolvimento da Educação (Brasil, 2007) e incluído no Plano Nacional da Educação PNE - (Brasil, 2014), o que the conferiu legitimidade para monitorar a evolução da qualidade da educação brasileira. Dentre as suas limitações está a correlação do Ideb com o perfil socioeconômico das escolas (Alves; Soares, 2013; Soares; Alves, 2013; Soares; Xavier, 2013).

Assim, seria razoável supor que a escola destacada no início deste artigo - que denominamos escola Alfa - poderia ter vantagens associadas à origem social dos seus alunos. Porém, essa escola está localizada numa região da cidade - a regional do Barreiro - que possui a média de renda da população mais baixa dentre as nove regionais de Belo Horizonte 4 . Mesmo num contexto urbano desvantajoso ela atingiu o maior Ideb do Ensino Fundamental I da cidade nas edições de 2009, 2011, 2013, 2015 e 2017. Por isso nos questionamos se o nível socioeconômico seria suficiente para explicar os resultados de escolas localizadas fora da área central da cidade.

Uma forma de se verificar isso é por meio de comparação com outras escolas. Neste artigo, apresentamos os resultados de uma pesquisa comparativa entre três escolas públicas estaduais em busca de pistas sobre as razões dos resultados diferenciados entre elas. A comparação entre escolas do mesmo sistema de ensino visou a controlar um fator de heterogeneidade entre elas. Estabelecimentos de ensino vinculados a dependências de ensino diferentes, com políticas educacionais definidas e executadas segundo parâmetros próprios poderia influir nos resultados. Vale registrar que, em Minas Gerais, a rede estadual mantém forte participação na oferta do ensino fundamental por meio de convênio com os municípios. Para esta investigação, tomamos como referência a literatura em eficácia escolar e efeito escola (Brooke; Soares, 2008).

\section{Avaliações externas e políticas de responsabilização}

A divulgação dos resultados das avaliações educacionais externas e do ldeb colocou grande foco na responsabilidade das escolas pela qualidade da educação (Brooke; Cunha, 2011). No Brasil essas avaliações são uma realidade há cerca de três décadas e o Sistema de Avaliação da Educação Básica - Saeb -, criado em 1990, é ainda o mais importante e abrangente modelo de avaliação do país (Brooke; Alves; Oliveira,

${ }^{3}$ Dentre várias reportagens sobre a escola, merece destaque a publicada no mais tradicional do estado, 0 Jornal Estado de Minas em 5 de setembro. Em 19/11/2014, o jornal francês La Croix enviou o jornalista Giles Biassette à cidade para conhecer os projetos da escola para entender o seu bom desempenho da escola em um país em que o sistema de ensino é mais conhecido pelas necessidades de ajustes.

${ }^{4}$ Segundos dados do Censo Demográfico de 2010 a renda média de Belo Horizonte era $\mathrm{R} \$ 1.497,33$. Na regional Barreiro, onde está localizada a escola Alfa, a renda média era $\mathrm{R} \$ 705,07$. A renda média mais alta foi observada na regional Centro-Sul, $\mathrm{R} \$ 3.915,67$, onde há maior oferta de serviços, equipamentos públicos e de lazer. Informações do Portal da Prefeitura Municipal de Belo Horizonte https://prefeitura.pbh.gov.br/estatisticas-e-indicadores.

\begin{tabular}{|c|c|c|c|c|c|}
\hline Regae: Rev. Gest. Aval. Educ. & Santa Maria & v. 9 & n. 18 & Pub. contínua 2020 & ? \\
\hline
\end{tabular}


2015). O Saeb produz informações que subsidiam a formulação, reformulação e o monitoramento das políticas públicas visando a contribuir para a melhoria da qualidade, equidade e eficiência do ensino e é "um dos mais amplos esforços empreendidos em nosso país de coleta, sistematização e análise de dados sobre os ensinos fundamental e médio" (Ferrão; Beltrão; Fernandes, 2001, p. 112).

Até 1995 o Saeb era uma avaliação amostral de escolas públicas. A partir de 1997 foi acrescentada uma amostra da rede privada. Em 2005 o Saeb foi reestruturado em duas avaliações: a Avaliação Nacional da Educação Básica - Aneb - e a Avaliação Nacional da Educação do Rendimento Escolar - Anresc -, conhecida como Prova Brasil. A Aneb manteve as características, os objetivos e os procedimentos da avaliação amostral efetuada pelo Saeb nas redes públicas e privadas. A Anresc, ou Prova Brasil, passou a avaliar de forma censitária, a cada dois anos, as escolas que atendessem aos critérios de no mínimo 30 estudantes matriculados na última etapa dos anos iniciais ( $5^{\circ}$ ano) ou dos anos finais ( $9^{\circ}$ ano) do ensino fundamental escolas públicas, permitindo gerar resultados por escola 5 .

O Ideb foi lançado pelo Inep em 2007. Esse indicador constitui uma política central do Plano de Metas Compromisso Todos pela Educação (Brasil, 2007) e combina informações do desempenho dos alunos em exames padronizados - média de desempenho dos estudantes em Língua Portuguesa e Matemática - obtido ao final das etapas de ensino - $5^{\underline{a}}$ e $9^{a}$ ano do ensino fundamental e $3^{\underline{a}}$ série do ensino médio - com informações sobre rendimento escolar obtida a partir do Censo da Educação Básica. Para o cálculo do Ideb das escolas e dos municípios é utilizado o desempenho dos alunos na Prova Brasil e, para o Ideb das unidades da Federação e o Brasil, o desempenho na Aneb (Fernandes, 2007).

O Ideb, cuja escala varia em um intervalo de 0 a 10 pontos, foi operacionalizado como um indicador de qualidade educacional a ser utilizado, tanto para orientar no planejamento de políticas públicas educacionais nos diferentes entes federativos município, Estados e União - e no financiamento da educação, quanto para servir como informativo à população em geral. Ele também é uma ferramenta para acompanhamento das metas de qualidade do PNE, que estabeleceu como meta que, em 2021, o ldeb do Brasil seja 6,0, média que, segundo o Inep, corresponde a um sistema educacional de qualidade comparável a dos países desenvolvidos.

Algumas pesquisas tem revelado resultados positivos produzidos pelas avaliações, como Alves (2007), que verificou a melhora do desempenho no Saeb nos Estados e municípios que implantaram sistemas próprios de avaliação externa. Mas há análises que sugerem os efeitos negativos causados pelo ranqueamento escolar sem contextualização (Souza; Oliveira, 2003, Soares; Xavier, 2013) e pela imposição das políticas de avaliação aos profissionais de educação sem que haja esclarecimentos (Freitas, 2007; Silva, 2007). As avaliações levaram ao aumento de políticas de responsabilização por resultados nos serviços públicos, fenômeno referido pelo termo em inglês accountability (Bonamino; Souza, 2012).

\footnotetext{
${ }^{5}$ Após a finalização desta pesquisa outras mudanças foram implantadas no Saeb, mas fogem ao escopo dos objetivos deste artigo. Informações sobre o Saeb, as avaliações que o compõe e a sua evolução estão disponíveis em http://portal.inep.gov.br/web/guest/educacao-basica/saeb.

\begin{tabular}{l|l|l|l|l|r|}
\hline Regae: Rev. Gest. Aval. Educ. & Santa Maria & v. 9 & n. 18 & Pub. contínua 2020 & p. 1-20
\end{tabular}
} 
Minas Gerais é considerado um caso em que a política de responsabilização foi implantada com consequências fortes - termo traduzido do inglês high-stakes - entre os anos 2003 a 2014, porque os resultados das avaliações eram utilizados para o cálculo de premiações que incidiam sobre o salário dos servidores (Bonamino; Sousa, 2012; Brooke; Cunha, 2011). O Estado possui uma avaliação educacional própria, o Sistema Mineiro de Avaliação - Simave -, do qual faz parte o Programa de Avaliação da Rede Pública de Educação Básica - Proeb -, que avalia todas as escolas públicas estaduais e de redes municipais que aderirem ao sistema de forma semelhante ao Saeb ${ }^{6}$. O Simave e Proeb passaram por algumas mudanças desde a sua criação e depois de 2014 reduziu o seu foco na responsabilização. Porém, na época da realização desta pesquisa, esse sistema de avaliação era ainda uma referência importante nas escolas públicas do Estado.

\section{Eficácia escolar e efeito escola}

As pesquisas em eficácia escolar mostram evidências de que a escola tem um papel relevante para o aprendizado dos alunos, mesmo considerando o impacto dos fatores associados à origem social dos estudantes. O efeito das escolas é um termo correlato e ocorre por meio de diversos fatores escolares que contribuem para o aprendizado dos alunos numa determinada escola, comparativamente ao que ele teria em outra com perfil discente semelhante.

Essas pesquisas tiveram origem como uma reação aos estudos educacionais, da década de 1960, que concluíram que a aprendizagem era influenciada pela origem social dos alunos e que a escola não tinha grande influência nessa determinação (Brooke; Soares, 2008). Nas décadas seguintes as pesquisas em eficácia escolar se voltaram para a tarefa de abrir a caixa preta da escola, uma vez que parecia não fazer sentido tratar as escolas como se fossem todas iguais. Pesquisadores passaram a investigar quais são as características de uma boa escola, ou seja, aquela que propicia ao aluno as melhores experiências para aquisição de habilidades cognitivas, o que passou a ser conhecido como pesquisa em eficácia escolar ou pesquisa sobre efeito das escolas. Esses estudos foram fundamentais para que os estabelecimentos de ensino voltassem a ser investigados (Mafra, 2003).

A partir da revisão dessa literatura e das condições objetivas para a realização da pesquisa, definimos três eixos de interesse para esta investigação que assumimos como hipóteses para explicar as diferenças entre escolas, quais sejam: a gestão escolar, baseada na liderança do diretor; o acompanhamento pedagógico, baseada na atuação do supervisor; as práticas escolares, baseadas na prática do professor.

A gestão escolar diz respeito a atuação do diretor, que deve administrar uma escola lidando simultaneamente com questões administrativas e pedagógicas, buscar um relacionamento próximo e tranquilo com a equipe de trabalho, sendo capaz de mobilizar os supervisores e os professores para o cumprimento dos objetivos educacionais estabelecidos na escola (Game, 2002). A literatura aponta que, nas escolas eficazes, os professores reconhecem a liderança do diretor, que se destaca por sua dedicação, atuação e formas de conduzir o grupo e a capacidade de criação (Alves; Franco, 2008).

${ }^{6}$ Informações sobre o Simave estão disponíveis em http://simave.educacao.mg.gov.br.

\begin{tabular}{l|l|l|l|l} 
Regae: Rev. Gest. Aval. Educ. & Santa Maria & v. 9 & n. 18 & Pub. contínua 2020
\end{tabular} p. $1-20$ 
O acompanhamento pedagógico acontece nas escolas estaduais de Minas Gerais pelos supervisores pedagógicos, que dão assistência ao professor na forma de planejamento, acompanhamento, coordenação, controle, avaliação e atualização do desenvolvimento no processo ensino-aprendizagem (Rangel, 1988). Essa é uma característica chave de escolas eficazes, pois permite o monitoramento do professor em sala de aula. Essa estrutura de monitoramento é uma referência sobre o que ensinar, pois permite elaborar um plano de curso estruturado a partir das necessidades dos alunos (Game, 2002).

O desempenho do professor em termos de seus conhecimentos, atitudes e habilidades com relação ao ensino aprendizagem são cernes da melhoria da qualidade da educação e também pelo apoio e suporte que o supervisor the dá, auxiliando e mediando suas dificuldades encontradas no decorrer do trabalho pedagógico (Lück, 2009). Nas práticas escolares, a ênfase está no cumprimento do currículo planejado, valorização de resultados, execução de práticas pedagógicas e altas expectativas em relação aos alunos por parte dos professores. Fernandes et al. (2010) revelaram que quando os professores têm conhecimento sobre os processos de avaliação em larga escala seus alunos apresentam maior desempenho. A correção do dever de casa tem efeitos nos resultados dos alunos (Alves; Franco, 2008; Alves; Xavier, 2016).

Nesta pesquisa buscamos compreender os processos internos das escolas que potencialmente podem influir na produção dos resultados aferidos pelos indicadores educacionais. Assumimos que o Ideb é uma referência importante para analisar a qualidade da educação, mas essa não pode ser resumida a essa medida, uma vez que a escola é uma instituição social marcada por uma grande complexidade.

\section{Metodologia}

Realizamos um estudo de caso comparativo em três escolas públicas estaduais de Belo Horizonte. Foi conduzida uma investigação que se preocupou com a interlocução dos dados quantitativos com a pesquisa qualitativa.

As escolas foram selecionadas por meio de uma análise estatística que permitiu comparar três unidades escolares estaduais de Belo Horizonte de Ensino Fundamental I, duas com alunado em situação socioeconômica similar, mas com a qualidade mensurada pelo Ideb 2013 - díspares e uma terceira escola com o nível socioeconômico mais baixo e qualidade destacada. Fazer um estudo com base nas escolas apenas com 0 maior Ideb não seria cabível, pois correríamos o risco de escolher escolas que recebem os melhores alunos e não aquelas que contribuem para uma efetiva aprendizagem desses.

Como mencionado o Ideb utilizado como um indicador de qualidade do ensino da educação básica e é expresso em uma escala de 0 a 10. A situação socioeconômica dos alunos foi mensurada pelo Índice de Nível Socioeconômico - Inse - produzido pelo Inep para contextualizar o desempenho das escolas ${ }^{7}$. A escala do Inse permite situar 0 conjunto dos alunos atendidos por cada escola em uma escala contínua de 0 a 100 .

Para chegar às três escolas analisamos a posição de 324 escolas públicas estaduais de Belo Horizonte que atendem aos anos iniciais do Ensino Fundamental num espaço cartesiano representado num gráfico de pontos. $O$ eixo y é o Ideb das escolas e 0

${ }^{7}$ Informações sobre o Inse em http://portal.inep.gov.br/indicadores-educacionais

\begin{tabular}{l|l|l|l|l|l|} 
Regae: Rev. Gest. Aval. Educ. & Santa Maria & v. 9 & n. 18 & Pub. contínua 2020 & p. 1-20
\end{tabular} 
eixo x é o Inse. Cada ponto representa uma escola. Os pontos destacados no gráfico são as três escolas selecionadas para o estudo, que foram denominadas por escola Alfa, escola Beta e escola Gama.

Gráfico 1 -

Relação entre o Ideb e Inse das escolas públicas estaduais na cidade de Belo Horizonte, primeira etapa do ensino fundamental no ano de 2013.

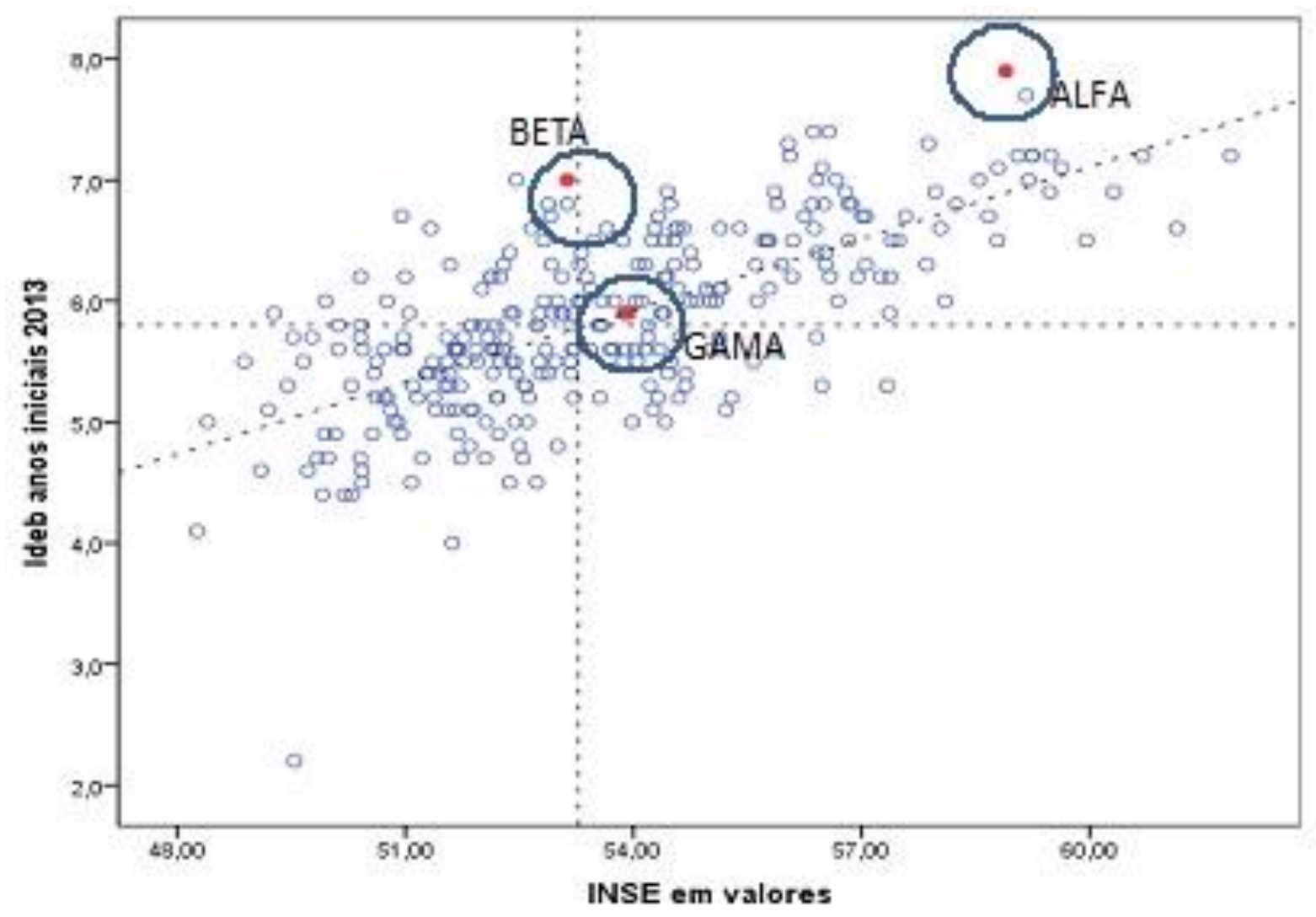

Fonte: autores.

A nuvem de pontos apresenta uma tendência ascendente, evidência da correlação positiva entre as variáveis Inse e Ideb. Ou seja, as escolas cujos alunos possuem melhor condição socioeconômica, mensurada pelo Inse, tendem a ter mais qualidade mensurada pelo Ideb. Para identificar estabelecimentos que podem se afastar dessa relação, traçamos duas linhas perpendiculares no gráfico para criar quadrantes. A linha horizontal separa as escolas com Ideb abaixo da média de Belo Horizonte $(5,86)$ das escolas com Ideb acima da média. A linha vertical separa as escolas com Inse abaixo da média de Belo Horizonte $(53,48)$ das escolas com NSE acima da média, à direita. A escola que constitui o primeiro foco de interesse da pesquisa - escola Alfa - é o ponto que está localizada no primeiro quadrante do plano, que reúne escolas com valores do Ideb e Inse acima da média. Nota-se que o ponto localizado no extremo mais alto do gráfico não está na posição mais extrema à direita, ou seja, embora ela tenha o ldeb mais alto não é a escola pública com o valor mais alto do Inse em Belo Horizonte.

Comparando a posição dessa escola com outras no plano cartesiano foi possível identificar um grupo pequeno de escolas com Inse mais baixo, mas com resultados destacados, mesmo que não tão alto. São os pontos no segundo quadrante - parte

\begin{tabular}{|l|l|l|l|l|l|} 
Regae: Rev. Gest. Aval. Educ. & Santa Maria & v. 9 & n. 18 & Pub. contínua 2020 & p. $1-20$
\end{tabular}


superior à esquerda. Também foi possível identificar escolas com Inse semelhante ao da escola de interesse, mas com resultados do Ideb mais baixos. São os pontos no quarto quadrante, parte inferior, à direta.

Dentre as opções delimitadas pelos quadrantes optamos por selecionar, além da escola Alfa, a escola Beta e a escola Gama destacadas no gráfico. Essas escolas nos permitiram controlar outros aspectos associados à heterogeneidade, pois as três pertencem à mesma rede estadual e estão localizadas na mesma região administrativa de Belo Horizonte: a regional do Barreiro.

O trabalho de campo envolveu a realização de entrevistas com profissionais da educação e observação. Antes da elaboração do roteiro de entrevista e da grade de observação analisamos um conjunto de indicadores educacionais desenvolvidos pelo Inep para conhecimento e caracterização das três escolas. As entrevistas seguiram um roteiro semiestruturado, elaborado em torno dos objetivos e hipóteses da pesquisa a partir da literatura revisada, mas também pelas observações diárias em contextos semelhantes. Basicamente a estrutura do roteiro continha quatro partes: a primeira foi reservada a questões relativas a identificação geral e formação dos entrevistados; a segunda dirigida às questões sobre currículo e planejamento; na terceira parte, utilizamos um estímulo com informações sobre os resultados das escolas, em perspectiva comparativa com outras escolas da região para verificar a apropriação dos resultados e a percepção das diferenças de resultados e perguntas que abordavam aspectos sobre a atuação da gestão e da supervisão escolar.

O estímulo empregado durante a entrevista consistiu na apresentação do gráfico 1 e de tabelas com os indicadores educacionais do Inep sobre as escolas. Ele foi utilizado para fornecer uma base para a interpretação de descobertas estatísticas, estimular a reflexão sobre cada escola em perspectiva comparada e para estudar o impacto deste sobre o entrevistado (Flick, 2009). Esse recurso não visou a testar conhecimentos, mas permitir que os profissionais das escolas lançassem hipóteses sobre o que estaria por trás dos resultados das escolas nas avaliações e nos indicadores educacionais a fim de identificar os fatores de eficácia escolar.

Foram entrevistados 14 profissionais das escolas, sendo três diretores, três supervisores e oito professores. Definimos como critério de seleção dos professores aqueles que ministravam, preferencialmente, aulas no $3^{\circ}$ ou $5^{\circ}$ ano do ensino fundamental, dentre professores antigos e novatos. Dentre os professores entrevistados, apenas um era do gênero masculino. A maioria deles são designados, $25 \%$ são efetivos, o que gera uma grande instabilidade no quadro docente. Sobre a formação $87,5 \%$ dos professores possuem curso superior e $37,5 \%$ possuem o curso de pós-graduação.

A pesquisa de campo envolveu o registro da observação realizada em alguns espaços das escolas a fim de obter uma visão geral do cotidiano, bem como ver e ouvir situações relacionadas ao objeto de estudo. Observamos a infraestrutura escolar e as dependências da direção e a supervisão, a sala dos professores e o pátio. Além disso em 
duas das escolas foi possível participar da reunião de Módulo $\|^{8}$. As observações nas escolas aconteceram no mesmo dia das entrevistas, marcadas previamente com as diretoras, quando fizemos anotações no caderno de campo.

Os resultados das entrevistas e das observações foram tratados pela técnica de análise de conteúdo (Bardin, 2009). As respostas dos participantes foram codificadas a partir dos três eixos de análise: liderança, acompanhamento pedagógico e práticas escolares. Foram criadas vinte e quatro categorias iniciais e reduzidas para dez categorias finais, que foram definidas como os fatores de eficácia escolar.

No apêndice $A$ apresentamos uma síntese dessa análise. O quadro A1 mostra as categorias iniciais por eixo, escola e sujeito entrevistado. Sintetizamos as informações de forma visual. Utilizamos cores diferentes de acordo com as respostas dos entrevistados e elaboramos uma legenda. Cada célula recebeu uma cor de acordo com o seguinte padrão: verde para respostas afirmativas, vermelha para respostas negativas e azul quando o entrevistado não soube responder ou não falou sobre a categoria. Um exemplo dessa categorização: a partir das respostas dos profissionais à pergunta: "Como você vê a atuação da gestão (diretora) na escola? Ela atua mais no pedagógico ou mais no administrativo?" Se o entrevistado disse que liderança atua mais no administrativo, marcamos cinza para liderança administrativa e preto para liderança pedagógica, se o entrevistado respondeu que ela atua nos dois, as duas lideranças ficaram branco, e se ele respondeu que atua só no pedagógico - como foi o caso do professor 3 da escola Alfa -, marcamos preto para liderança administrativa e cinza para a liderança pedagógica. Buscamos perceber sempre se cada um dos entrevistados fazia qualquer menção em alguma das categorias. $O$ quadro $A 1$, do apêndice, nos permitiu visualizar as convergências e divergências entre os sujeitos ou escolas.

\section{Resultados}

A regional Barreiro, de Belo Horizonte, embora compartilhem a gestão administrativa do município, internamente possui diferenças entre os bairros, as escolas e respectivos perfis de alunos que não são captadas nas pesquisas demográficas.

No trabalho de campo constatamos que a escola Alfa apresenta vantagens socioeconômicas em relação às outras duas. Ela está situada em um bairro tipicamente residencial, onde as casas têm padrão construtivo muito bom. A escola Alfa é menor do que as outras e tem um perfil social dos alunos mais favorecido. Neste aspecto as escolas Beta e Gama se assemelham, possuem o Inse e as características dos alunos bem próximos. A escola Beta está situada em um bairro mais industrial e a Gama em um bairro tipicamente de padrão construtivo popular.

De acordo com os indicadores educacionais do Inep $^{9}$ a escola Beta tem menos professores com formação adequada (79\%) e regularidade dos professores menor classificada pelo Inep como média-alta. Já as escolas Alfa e Gama se assemelham em relação à formação de seus professores - cerca de $90 \%$ têm formação adequada - e na

\footnotetext{
8 A reunião Modulo II está disposta no artigo 10 da resolução n. 2.253, de 9 de janeiro de 2013. Das 8 horas semanais destinadas às atividades extraclasse para os professores de educação básica com jornada de 24h, $4 \mathrm{~h}$ semanais devem ser cumpridos na própria escola e destas $4 \mathrm{~h}$ até $2 \mathrm{~h}$ devem ser dedicadas a reuniões de caráter mais coletivo.

9 Os indicadores educacionais produzidos pelo Inep e suas notas técnicas estão disponíveis em http://portal.inep.gov.br/web/guest/indicadores-educacionais.

\begin{tabular}{|l|l|l|l|l|r|}
\hline Regae: Rev. Gest. Aval. Educ. & Santa Maria & v. 9 & n. 18 & Pub. contínua 2020 & p. 1-20
\end{tabular}
} 
sua regularidade - classificada pelo Inep como média-baixa. De acordo com o indicador de complexidade de gestão do Inep - que sintetiza em um nível o número de alunos, etapas, modalidades de ensino ofertadas e turnos de funcionamento do estabelecimento de ensino - a escola Alfa e a escola Gama são classificadas pelo Inep no nível 2, uma complexidade baixa. A escola Beta está classificada no nível 6, complexidade mais elevada, o que implica em um contexto com mais desafios para os profissionais da escola.

\section{Fatores de eficácia escolar}

Pelo quadro $A 1$ do apêndice podemos observar que, de uma forma geral, as escolas têm mais convergências do que divergências nas categorias. No eixo liderança, centrado no papel da direção, observamos predomínio de consensos. No eixo acompanhamento pedagógico, centrado na atuação do especialista de supervisão, há muitas convergências. Mais duas categorias têm divergências importante: o processo de formação de turmas e as reuniões do Módulo II, destinada às atividades extraclasse dos professores. No eixo práticas pedagógicas, voltados para os professores, embora a maioria das opiniões seja convergente, duas categorias destoam: o recurso do dever de casa e as expectativas de aprendizagem.

\section{Eixo: liderança}

Neste eixo as categorias iniciais registradas no apêndice foram agrupadas em quatro categorias finais: liderança, foco nos resultados, incentivo e rede de apoio. Destacaremos as três primeiras, que possuem divergências.

\section{Liderança}

Quase todos os estudos de eficácia escolar mostram a liderança como fator-chave, tanto na escola primária, quanto na secundária (Sammons, 2008). Constatamos que as três diretoras são líderes, conseguem atuar tanto no setor pedagógico, quanto no setor administrativo. As questões administrativas demandam muito tempo de trabalho, que chega a mais do que 40 horas semanais. Mas as três afirmam atuar mais no pedagógico, não deixando de lado as questões administrativas.

As diretoras da Alfa e da Gama conseguem atuar com mais frequência em ações pedagógicas porque são escolas que atendem apenas o Ensino Fundamental I. Elas acompanham o trabalho dos professores, o desenvolvimento dos alunos e com frequência frequentam a sala de aula:

Eu procuro acompanhar desde a elaboração, a execução e o acompanhamento dos planejamentos, que é fundamental, porque o papel por si só não gera aprendizagem. O acompanhamento é diário, de estar vendo as atividades dos meninos, vendo detalhe. [...] É um processo contínuo de acompanhar a frequência, de acompanhar o fazer, de acompanhar a disciplina, de acompanhar o que está sendo feito, de sugerir e acompanhar os projetos, eu gosto de participar da elaboração dos projetos, da execução e de pensar nos desdobramentos do ganho para os alunos e para a comunidade. Então é sempre fazendo o hoje e o amanhã. (Diretora da escola Alfa)

Eu atuo muito no pedagógico, acompanhando os professores, planejando com supervisoras, acompanhando as intervenções daquelas crianças que não estão no nível que deveriam estar, as intervenções pedagógicas, então eu acompanho 
de perto as crianças para que elas possam chegar ao nível que todos os outros estão, e na formação dos professores, os módulos eu planejo junto e sei falar o resultado todos os anos da minha escola, então eu atuo no pedagógico muito e delego funções no administrativo e no financeiro. (Diretora da escola Gama)

Já a diretora da escola Beta relatou que só vai à sala de aula quando necessário, por exemplo, quando um professor recebe reclamação sobre suas aulas pouco atrativas ou quando recebe reclamação generalizada de uma determinada turma. Isso se deve ao fato de a escola ser grande - complexidade da gestão Nível 6 -, gerando inúmeras demandas: "Sempre pautei meu trabalho na dimensão da gestão escolar pedagógica, que sempre foi meu foco, para a qual todas as demais convergem" (Diretora da escola Beta).

Vale registrar que as três diretoras estão há anos na função e assumiram pelo processo de eleição. A diretora da escola Alfa está no cargo há 16 anos, a da escola Beta há 20 anos e a da escola Gama há 6 anos.

\section{Foco nos resultados}

Todos os entrevistados afirmaram que são estabelecidas metas para a aprendizagem dos alunos e que as mesmas são compartilhadas durante a reunião de Módulo II. As diretoras informam que existe uma preocupação com os resultados internos e externos e que existe reflexão visando o replanejamento do trabalho pedagógico. Parece haver benefícios específicos no comprometimento ativo do diretor no monitoramento do desempenho e progresso dos alunos (Sammons, 2008).

As três diretoras dão importância aos sistemas de monitoramento do desempenho dos alunos como o Proeb - avaliação estadual -, a Prova Brasil - avaliação nacional - e preparam os alunos para essas avaliações por meio de simulados e atividades direcionadas. Vale registrar que a diretora da escola Alfa atribui ao foco nos resultados o fato de a escola se manter como a melhor escola da cidade por cinco edições do ldeb:

O esforço da escola é de o aluno aprender. Quando ele tem um bom resultado é sinal que ele está aprendendo. Apesar de ser um processo complexo, trabalhoso, mas é simples, né? Ensinou direito, aprendeu. Então se ele aprendeu tem resultado, né? Então assim, sensação de satisfação, né? Ver que o esforço não é em vão e que o objetivo maior da escola - de que o aluno aprenda - está sendo alcançado. Eu falo muito que a gente não pode fazer por fazer, nós temos que fazer o que nós viemos fazer e o que nós viemos fazer é oportunizar aprendizagem (Diretora da escola Alfa).

Podemos, portanto, constatar que as políticas de responsabilização, com foco nos resultados, estão inseridas nas escolas, sobretudo na escola Alfa, um padrão que corrobora com os estudos anteriores (Alves, 2007; Bonamino; Souza, 2011).

\section{Incentivo}

A maioria dos professores afirma sempre receber um feedback de seu trabalho. Segunda a literatura em eficácia escolar não basta apenas o diretor fazer reuniões de planejamento, estabelecer metas e elaborar planos se depois ele não acompanhar e motivar a sua equipe para que as ações saiam do papel e as metas sejam cumpridas (Game, 2002). Assim, nesse quesito o retorno das diretoras Alfa e Beta se assemelham, 
os professores dizem que além do feedback também recebem comentários sobre seus trabalhos. Já na escola Gama uma professora relatou que a falta de tempo da diretora impede a avaliação de seu trabalho, mas não deixa de elogiar a atuação da direção.

Todos os professores afirmam que são motivados pela direção, mas é interessante observar que cada diretora faz isso de uma forma. A diretora da escola Alfa motiva em seu acompanhamento bem próximo ao trabalho do professor. A diretora da escola Beta motiva cuidando das condições de trabalho do professor. Na escola Gama a diretora motiva os professores fazendo elogios e agradecimentos durante as reuniões. Isso também ocorre com os professores das escolas Alfa e Beta, que relatam perceber um reconhecimento de seu trabalho em festas comemorativas, café da manhã e almoço no dia de reunião aos sábados.

\section{Eixo: acompanhamento pedagógico}

Neste eixo as categoriais iniciais descritas no apêndice foram agrupadas em duas categorias finais: acompanhamento do professor e monitoramento da aprendizagem dos alunos.

\section{Acompanhamento do professor}

A categoria inicial formação de turma foi incluída nessa categoria final porque o perfil da turma tem impacto na prática docente. De acordo com a literatura em eficácia escolar, efeito escola se estrutura pela forma como as escolas organizam os alunos em turmas e esse nível - a turma - é muito importante para a investigação do efeito escola (Alves; Soares, 2007; Alves; Franco, 2008; Barbosa; Fernandes, 2001). Em quase sua totalidade os entrevistados da escola Alfa afirmam organizar as turmas de forma homogênea. Já os entrevistados das escolas Beta e Gama dizem organizar as turmas de forma heterogênea, mas agrupam os alunos de forma homogênea quando necessário:

Nessa escola a enturmação é feita pelo cognitivo. A turma faz uma avaliação diagnóstica e separa de acordo com o cognitivo da criança se é turma $A, B, C$ e $D$. As salas são homogêneas, não são heterogêneas aqui não. $A$ turma " $A$ " é a melhor turma, a "B" é uma sala mediana, a "C" é a que precisa de uma maior intervenção. [...] as últimas salas, na maioria das vezes, ficam para o professor designado e o efetivo pega as melhores. (Professor 3 da escola Alfa)

A enturmação é feita assim: os meninos classificados em $A$ são distribuídos em 3 turmas, o B em 3 turmas, o $C$ em 3 turmas. Aqui a enturmação é heterogênea, mas quando necessário fazemos o reagrupamento dos alunos, colocamos os alunos com as mesmas dificuldades em uma sala e quando a dificuldade é sanada eles retornam para sua sala de origem. (Supervisora da escola Beta)

Numa turma eu tenho vários níveis de aprendizagem. Então a gente trabalha assim até mais ou menos o meio do ano com esses meninos misturados. Então depois a diretora resolve fazer uma intervenção, uma reclassificação e vê, se tiver o aprendizado, está fluindo beleza, se não ela tira da sala os alunos que estão com mais dificuldade, neste caso só quem não está alfabetizado que ela tira e monta uma sala dos mais fracos. E ali existe um trabalho da supervisora, da diretora, para tentar alfabetizar esses alunos. (Professor 2 da escola Gama) 
Para entender as consequências da formação de turmas homogêneas pelo cognitivo da escola Alfa fizemos uma análise auxiliar dos dados das Prova Brasil da escola, descrevendo o percentual de alunos por nível de desempenho em cada turma ${ }^{10}$. As diferenças entre as turmas da escola Alfa são evidentes: a melhor turma possui quase $90 \%$ de alunos no nível avançado em Língua Portuguesa e mais de $90 \%$ em Matemática. Nas outras turmas não há alunos no nível abaixo do básico em Língua Portuguesa e em apenas uma delas há $4 \%$ de alunos nesse nível em Matemática. Isso parece ser uma forma de relativizar o efeito perverso da enturmação homogênea na escola Alfa. Nas escola Beta e Gama há alunos com desempenho abaixo do básico em Matemática todos as turmas e quase todas em Leitura.

A literatura em eficácia escolar e efeito escola mostra que há maior variação no nível das salas de aula do que no nível das escolas. Hallinan (1994) argumenta que a formação de turmas homogêneas melhora o ensino e aumenta a sua eficácia ao permitir que os professores adaptem a aula ao nível dos alunos. Mas a prática cria oportunidades desiguais de aprendizado, pois as escolas estabelecem objetivos bem mais baixos para as turmas com dificuldade de aprendizagem (Alves; Soares, 2007).

O currículo - planejamento e acompanhamento - é outra categoria importante do acompanhamento do professor. Nos últimos anos a discussão sobre o currículo escolar tem sido muito associada às avaliações educacionais. A divulgação dos resultados da Prova Brasil e do Ideb por escola de certa forma fez com que muitos sistemas de ensino passassem a pressionar os estabelecimentos de ensino com vistas a elevar as suas médias (Bonamino; Souza, 2012). Nesse ponto houve consenso entre os entrevistados, que afirmaram que o currículo é baseado no Currículo Básico Comum - CBC - proposto pela Secretaria Estadual de Educação. Na escola Gama o material apresentado por uma supervisora é idêntico ao fornecido pela SEE, sem qualquer alteração. Já na escola Alfa e a escola Beta há alguma adaptação: o currículo é estruturado e dividido por bimestre de todos os anos de ensino. Mas apenas na escola Alfa parece acontecer um diálogo com o professor para a elaboração desse currículo no início do ano.

Um ponto divergente entre as escolas é o uso do horário extraclasse para atividades pedagógicas, sumarizado na categoria final Reuniões do Módulo II semanal. Nestas deve ser realizado o atendimento ao professor durante a aula especializada de Educação Física. Porém, a única escola que cumpre esse acompanhamento é a escola Alfa. Os professores trabalham quatro vezes por semana, 30 minutos após o horário e sempre são acompanhados pela equipe gestora:

Existe esse acompanhamento. A gente retoma, se for necessário. Se a gente, por exemplo, trabalha os grupos ortográficos e o aluno permaneceu com dificuldade, a gente retoma, mas a supervisora sempre junto. Ela me acompanha toda terça que é minha educação física e no módulo. A gente tem o módulo também em conjunto com as quatro professoras de cada ano, após a aula. (Professora 1 da escola Alfa)

Nas escolas Beta e Gama todos os entrevistados afirmaram que o supervisor realiza o acompanhamento do currículo e do trabalho do professor, mas relataram que as reuniões de Módulo II não acontecem semanalmente.

10 Os níveis de desempenho analisados são os mesmos adotados no portal Qedu, que reúne dados produzidos elo Inep. Disponível em: www.qedu.org.br.

\begin{tabular}{|l|c|c|c|c|} 
Regae: Rev. Gest. Aval. Educ. & Santa Maria & v. 9 & n. 18 & Pub. contínua 2020 \\
\hline
\end{tabular} 
- Monitoramento da aprendizagem

Esta categoria final, considerada importante na literatura em eficácia escolar, é composta por uma categoria inicial: o monitoramento da aprendizagem. $O$ supervisor deve ter estratégias para o monitoramento do desempenho e progresso dos alunos, das salas de aula e da escola como um todo (Medina, 2002). Segundo Nérici (1983) o supervisor deve gerenciar as atividades educacionais, atuando como mediador no processo que se refere ao envolvimento administrativo com os docentes, sendo facilitador e sugerindo novas metas, recursos e técnicas, mostrando sempre o que se deve ser melhorado através de críticas construtivas para com os docentes com quem trabalha.

$\mathrm{Na}$ escola Alfa a supervisora acompanha os alunos por meio das atividades e provas que são aplicadas pelo professor e assinadas pela supervisora. Nas turmas consideradas fracas - lembrando que nessa escola a enturmação é homogênea -, todas as avaliações também passam para ser analisadas com a direção da escola. Além disso a supervisora é responsável bimestralmente por tomar leitura e fazer arguição dos fatos fundamentais de todos os alunos. Na escola Beta a supervisora acompanha os alunos com provas diagnósticas que ela própria elabora, aplica e corrige, além de avaliar a leitura dos alunos. $\mathrm{Na}$ escola Gama a supervisora acompanha o aluno pelos resultados internos e visitas a sala de aula. A atuação da supervisão no monitoramento dos alunos foi constatada durante o período de observação e nas falas dos entrevistados.

\section{Eixo: práticas pedagógicas}

Este eixo foi constituído pelo agrupamento de nove categorias iniciais em quatro categorias finais: planejamento, execução das práticas pedagógicas, expectativa de aprendizagem e avaliação da aprendizagem.

\section{Planejamento}

Esta categoria contempla as categorias iniciais: cumprimento do currículo e apoio a criação da BNCC. Na época do trabalho de campo, a BNCC, prevista no PNE aprovado em 2014, estava em discussão. Todos os nossos entrevistados afirmam que os professores cumprem o currículo que foi planejado e apenas dois deles não concordam com a criação da BNCC, como a professora 1 da escola Gama: "Para mim isso não seria muito importante, a escola que tem que desenvolver o seu currículo". Na escola Alfa um professor duvidava do sucesso na implantação da BNCC:

Ele [o governo] quer que o currículo seja igual, né, mas acaba que não consegue ficar igual. No meu ponto de vista, eu acho que não consegue. Eu acho que não funciona não, tem as particularidades. Por exemplo, aqui a gente segue na íntegra o currículo, mas tem escolas aí, e eu falo assim porque já estive em outra escola, que não segue. Não tem esse acompanhamento que a gente da direção, da supervisão, não tem um profissional ali para dar suporte e te dar orientação. (Professor 1 da escola Alfa)

Mas a maioria dos entrevistados apoiam a BNCC:

Ótimo, porque nós vamos ter um padrão a ser seguido por todas as escolas, não deixando de fazer as intervenções de cada região. A criança que está lá no Nordeste vai aprender o conteúdo, mas o professor lá vai 
trabalhar aspectos da região do Nordeste, típicos daquela região. Aqui em Minas Gerais nós vamos trabalhar típicos da nossa região. (Professor 3 da escola Alfa)

Bom, eu acredito que nós temos que ter uma base sim, geral, o mínimo que todo mundo tem que saber, porque a língua é a mesma e a parte diversificada que é de acordo com cada estado, mas eu sou a favor, porque você precisa deixar claro o quê, que o menino precisa aprender em cada ano. (Supervisora da escola Beta)

\section{Altas expectativas de aprendizagem}

Expectativas positivas quanto ao desempenho do aluno, especialmente entre os professores é uma das características mais importantes das escolas eficazes (Sammons, 2008). Por essa razão a categoria inicial altas expectativa de aprendizagem se manteve como categoria final, sem agrupamento. Percebemos uma gradação das respostas entre os entrevistados por escola, estando a escola Alfa em melhor situação, seguido pela Escola Gama e, por fim, pela Escola Beta. Foi classificado com altas expectativa quando os entrevistados responderam que a maioria de seus alunos irão finalizar o ensino superior. No entanto, com exceção dos entrevistados na escola Alfa, a maioria acredita que seus alunos não têm condições de ingressar no ensino superior, conforme a professora da escola Beta:

Eu quero que eles vão para o quarto ano lendo melhor do que tá lendo agora e o que eu passei pra eles, que eles realmente tenham aprendido. A minha turma eu acho que todos vão terminar o Ensino Fundamental, é uma turma de terceiro ano muito boa. O Ensino Médio a maioria irá concluir, já o ensino superior aí eu já acho que nem todos. (Professora 2 da escola Beta)

\section{Avaliação da aprendizagem}

A avaliação é vista como um instrumento a serviço da aprendizagem dos conteúdos e habilidades ensinadas. Mecanismos bem estabelecidos para o monitoramento do desempenho e progresso dos alunos, das salas de aula, da escola como um todo e dos programas de melhoramento são características importantes de muitas escolas eficazes. (Sammons, 2008). Esta categoria obteve 100\% das respostas afirmativas. Há uma grande convergência de opiniões entre os entrevistados: todos relatam preparar os alunos para as avaliações externas.

Porém, segundo Afonso (2009) existe uma tensão entre a avaliação como instrumento de controle e como ferramenta para desenvolver uma nova forma de trabalho com o objetivo de alcançar as metas estabelecidas a partir dos resultados das avaliações externas, que tendem a elaborar formas que condicionam as opções pedagógicas e profissionais. Todos os entrevistados afirmam sofrer influência das avaliações externas, como, por exemplo, explicou uma professora da escola Alfa: "Eu acho que sim, porque quando é feita essa avaliação, que vem o resultado, que a gente faz a reflexão, a gente muda o posicionamento de alguns focos, faz um novo planejamento" (Professora 2 da escola Alfa). 


\section{Considerações finais}

O objetivo desta pesquisa foi e identificar fatores escolares relacionados à gestão escolar, ao acompanhamento pedagógico e às práticas escolares associados aos resultados no Ideb em três escolas públicas de Ensino Fundamental I localizadas numa região distante do centro de Belo Horizonte. A pesquisa foi motivada pelo resultado de uma delas - a escola Alfa - que apresentou seguidamente os resultados mais destacados no Ideb. Para controlar o impacto de fatores externos à escola - notadamente o nível socioeconômico dos seus alunos - realizamos uma pesquisa comparativa com outras duas escolas com resultados divergentes, mas selecionadas segundo critérios que asseguraram a pertinência da comparação entre elas.

O que observamos nas três escolas corrobora a literatura sobre eficácia escolar no Brasil (Alves; Franco, 2008; Game, 2002). Porém, observamos que há uma configuração própria de cada uma delas. Os fatores identificados não devem ser considerados de forma independente um do outro. No diagrama da figura 1, buscamos sintetizar as interrelações entre os fatores.

Figura 1 -

Fatores de eficácia escolar.

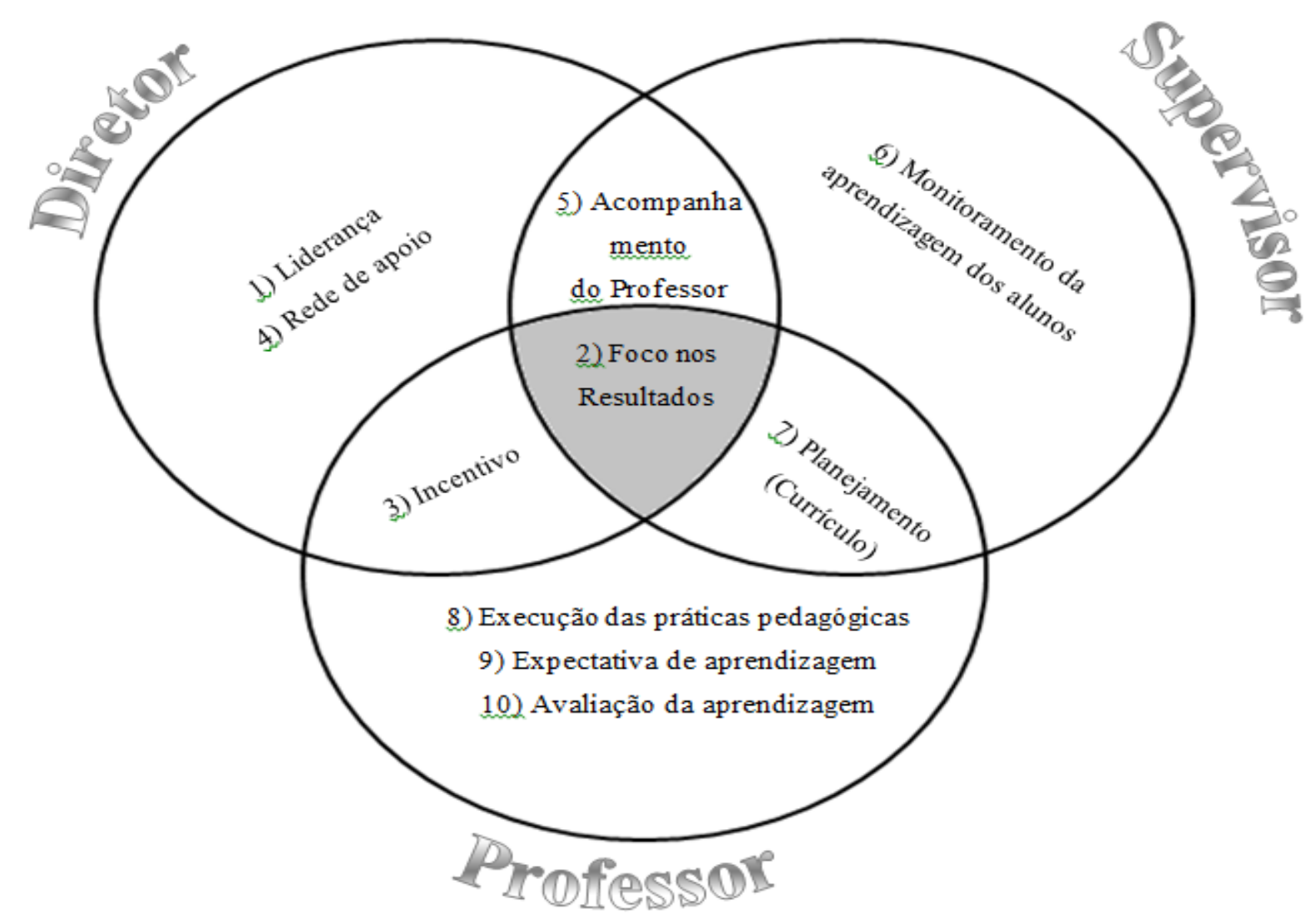

Fonte: autores.

Essas características se fazem mais presentes na escola Alfa onde, além de uma liderança eficaz, há um acompanhamento pedagógico constante e muito próximo de alunos e professores. Inegavelmente o contexto social the favorece em comparação com as outras, mas isso não obscurece a existência de práticas pedagógicas que também 
contribuem para o ensino e aprendizado. As escolas Beta e Gama também contam com uma liderança atuante, mas possuem menos atributos pedagógicos destacados, são menos consistentes, sobretudo a escola Gama.

A escola Beta é um exemplo de que a escola pública pode atuar para mudar e melhorar a realidade de seus alunos. Ela apresenta algumas características que dificultam o seu trabalho - maior complexidade, menos regularidade docente, menos professores com formação adequada e alunos com perfis sociais menos favorecidos - se comparados com alunos da Alfa. Apesar disso, apresenta características de eficácia e os seus resultados crescentes ao longo das avaliações confirmam isso.

A escola Gama, apesar de menos complexa e Inse semelhante à escola Beta, é a escola em que encontramos menos características de escolas eficazes. Entretanto suspeitamos que o Inse dessa escola possa ter sido superestimado pelo Inep. Numa análise auxiliar com dados da Prova Brasil não incluída neste texto observamos que muitos alunos dessa escola não responderam ao questionário contextual utilizado pelo Inep para estimar o Inse em comparação com as outras duas escolas. Os dados ausentes afetam as estimativas desse indicador conforme no estudo que foi replicado pelo Inep na estimação do Inse (Alves; Soares; Xavier, 2014). É possível que a realidade social seja menos favorável do que imaginamos quando fizemos a sua seleção.

As três escolas parecem terem incorporados princípios das políticas de responsabilização que, no Estado de Minas Gerais, foi forte a partir de 2003 (Bonamino; Souza, 2011; Brooke; Cunha, 2011). Isso mostra que as políticas estaduais de longo prazo conseguem influir nos estabelecimentos de ensino. Porém, essas políticas não acontecem no vácuo. Encontramos nas escolas lideranças legitimadas pela comunidade escolar para conduzir o processo de ensino-aprendizado, mas que encontram condições da oferta educativa distintas. São limites reais que dependem do apoio das políticas educacionais para a valorização da escola pública e da autonomia das escolas para superá-los.

\section{Referências}

AFONSO, Almerindo J. Nem tudo o que conta é mensurável ou comparável: crítica à accountability baseada em testes estandardizados e rankings escolares. Revista Lusófona de Educação, Lisboa, v. 13, n.1, 2009, p. 13-29.

ALVES, Fátima. Qualidade da educação fundamental: integrando desempenho e fluxo escolar. Ensaio: Avaliação e Políticas Públicas em Educação, Rio de Janeiro, v. 15, n. 57, 2007, p. 525-542.

ALVES, Maria Teresa G.; FRANCO, Creso. A pesquisa em eficácia escolar no Brasil: evidências sobre o efeito das escolas e fatores associados à eficácia escolar. In: BROOKE, Nigel; SOARES, José Francisco (ed.). Pesquisa em eficácia escolar: origem e trajetórias. Belo Horizonte: UFMG, 2008, p. 482-500.

ALVES, Maria Teresa G.; SOARES, José Francisco. Efeito-escola e estratificação escolar: o impacto do uso da habilidade dos alunos na composição de turmas. Educação em Revista, Belo Horizonte, n. 45, 2007, p.25-59.

ALVES, Maria Teresa G.; SOARES, José Francisco. Contexto escolar e indicadores educacionais: condições desiguais para a efetivação de uma política de avaliação educacional. Educação e Pesquisa, São Paulo, v. 39, n. 1, 2013, p. 177-194. 
ALVES, Maria Teresa G.; SOARES, José Francisco, XAVIER, Flavia P. Índice socioeconômico das escolas de educação básica brasileiras. Ensaio: Avaliação e Políticas Públicas em Educação, São Paulo, v. 22, 2014, p. 671-703.

BARBOSA, Maria Eugénia Ferrão; FERNANDES, Cristiano. A escola brasileira faz diferença? Uma investigação dos efeitos da escola na proficiência em matemática dos alunos da 4⿳亠丷 série. In: FRANCO, Creso (org.). Avaliação, ciclos e promoção na educação. Porto Alegre: Artmed, 2001, p. 155-172.

BARDIN, Laurence. Análise de conteúdo. Lisboa: Edições 70, 2009.

BONAMINO, Alícia; SOUSA, Sandra Zákia. Três gerações de avaliação da educação básica no Brasil: interfaces com o currículo na escola. Educação e Pesquisa, São Paulo, v. 38, n. 2, 2012, p. 373-388.

BRASIL. Decreto 6.094, de 24 de abril de 2007. Dispõe sobre a implementação do Plano de Metas Compromisso Todos pela Educação. Brasília: Governo Federal, 2007.

BRASIL. Lei n.13.005, de 25 de julho de 2014. Aprova o Plano Nacional de Educação e dá outras providências. Brasília: Governo Federal, 2014.

BRESSOUX, Pascal. As pesquisas sobre o efeito-escola e o efeito-professor. Educação em Revista, Belo Horizonte, n. 38, 2003, p. 17-88.

BROOKE, Nigel; ALVES, Maria Teresa G.; OLIVEIRA, Lina Kátia M (org.). A avaliação da educação básica: a experiência brasileira. Belo Horizonte: Fino Traço, 2015.

BROOKE, Nigel; CUNHA, Maria Amália Almeida. A avaliação externa como instrumento da gestão educacional nos estados. Estudos \& Pesquisas Educacionais, São Paulo, v. 2, 2011, p. 17-79.

BROOKE, Nigel; SOARES, José Francisco (org.). Pesquisa em eficácia escolar: origem e trajetórias. Belo Horizonte: UFMG, 2008.

CURY. Carlos Roberto Jamil. Qualidade em educação. Nuances: estudos sobre educação, Presidente Prudente, v. 17, n. 18, 2010, p. 15-31.

FERNANDES, Reynaldo. Índice de desenvolvimento da educação básica (Ideb). Brasília: Inep, 2007.

FERRÃO, Maria Eugénia et al. O Saeb: Sistema Nacional de Avaliação da Educação Básica: objetivos, características e contribuições na investigação da escola eficaz. Revista Brasileira de Estudos de População, Rio de Janeiro, v. 18, n.1/2, 2001, p. 111-130.

FLICK, Uwe. Desenho da pesquisa qualitativa. Porto Alegre: Bookman, Artmed, 2009.

FREITAS, Helena Costa Lopes. A (nova) política de formação de professores: a prioridade postergada. Educ. Soc., Campinas, v. 28, n. 100, 2007, p. 1203-1230.

GAME - GRUPO DE AVALIAÇÃO E MEDIDAS EDUCACIONAIS. Escola eficaz: um estudo de caso em três escolas da rede pública do Estado de Minas Gerais. Relatório de Pesquisa. SOARES, José Francisco (coord.). Belo Horizonte, UFMG, 2002.

GUSMÃO, Joana Buarque. A construção da noção de qualidade da educação. Ensaio: aval. pol. públ. educ., Rio de Janeiro, v. 21, n. 79, 2013, p. 299-322.

HALLINAN, Maurren T. School differences in tracking effects on achievement. Social Forces, Chapel Hill, v. 72, n, 3, 1994, p. 799-820.

LÜCK, Heloisa. Dimensões de gestão escolar e suas competências. Curitiba: Positivo, 2009. 
MAFRA, Leila. A. A sociologia dos estabelecimentos escolares: passado e presente de um campo de pesquisa em reconstrução. In: ZAGO, Nadir; CARVALHO, Marília P et. al. (ed.). Itinerários de pesquisa: perspectivas qualitativas em sociologia da educação. Rio de Janeiro: DP\&A, 2003, p.109-136.

MEDINA, Antônia da Silva. Supervisão escolar. Porto Alegre: AGE, 2002.

NÉRICl, Imidio. Introdução a Supervisão escolar. São Paulo: Atlas, 1983.

OLIVEIRA, Romualdo Portela de; ARAUJO, Gilda C. Qualidade do ensino: uma nova dimensão da luta pelo direito à educação. Revista Brasileira de Educação, Rio de Janeiro, n. 28, 2005, p. 5-23.

PAULA, Gustavo Bruno. A influência do território sobre as escolhas escolares das famílias: um estudo em uma região da periferia de Belo Horizonte. Belo Horizonte: UFSM, 2015. 103f. Dissertação (mestrado em Educação). Universidade Federal de Minas Gerais.

RANGEL, Mary. Supervisão pedagógica: um modelo. Petrópolis: Vozes, 1988.

SAMMONS, Pamela. As características-chave das escolas eficazes. IN: BROOKE, Nigel; SOARES, José Francisco. Pesquisa em eficácia escolar: origem e trajetórias. Belo Horizonte: UFMG, 2008, p. 335-392.

SILVA, Maria Juliana de Almeida. O sistema mineiro de avaliação da educação pública: impactos na escola fundamental de Uberlândia. REICE. Revista Iberoamericana sobre Calidad, Eficacia y Cambio en Educación, Madrid, v. 5, 2007, p. 241-253.

SOARES, José Francisco; ALVES, Maria Teresa G. Contextualização dos resultados das escolas de ensino fundamental. Retratos da Escola, Brasília, v. 7, n. 12, p. 2013, p. 145158.

SOARES, José Francisco, ALVES, Maria Teresa G.; XAVIER, Flavia P. Effects of Brazilian schools on student learning. Assessment in Education, 2016, p. 1-23.

SOARES, José Francisco; XAVIER, Flavia P. Pressupostos educacionais e estatísticos do IDEB. Educação e Sociedade, Campinas, v. 34, n. 124, 2013, p. 903-924.

SOUZA, Sandra Zákia; OLIVEIRA, Romualdo Portela. Políticas de avaliação da educação e quase mercado no Brasil. Educação e Sociedade, Campinas, v. 24, n. 84, 2003, p. 873895.

WILLMS, J. Douglas. Monitoring school performance. Washington: The Falmer Press, 1992. 


\section{Apêndice}

Quadro A1 -

Classificação das categorias de análise.

\begin{tabular}{|c|c|c|c|c|c|c|c|c|c|c|c|c|c|c|c|c|}
\hline \multirow[b]{2}{*}{ Eixo } & \multirow[b]{2}{*}{ Categoria Inicial } & \multirow[b]{2}{*}{ Categoria final } & \multicolumn{5}{|c|}{ Escola Alfa } & \multicolumn{5}{|c|}{ Escola Beta } & \multicolumn{4}{|c|}{ Escola Gama } \\
\hline & & & 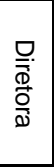 & 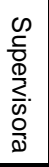 & 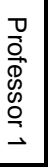 & 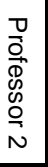 & 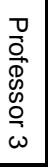 & 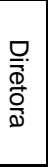 & 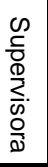 & 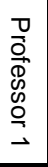 & 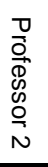 & 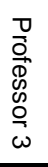 & 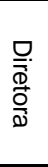 & 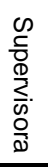 & 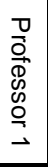 & 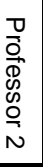 \\
\hline \multirow{9}{*}{ 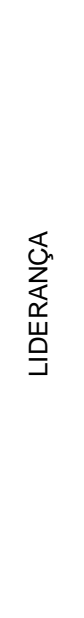 } & 1) Liderança Administrativa & \multirow{2}{*}{ 1) Liderança } & & & & & & & & & & & & & & \\
\hline & 2) Liderança Pedagógica & & & & & & & & & & & & & & & \\
\hline & 3) Estabelecimento de metas & \multirow{3}{*}{ 2) Foco nos resultados } & & & & & & & & & & & & & & \\
\hline & $\begin{array}{l}\text { 4) Resultados externos } \\
\text { compartilhados }\end{array}$ & & & & & & & & & & & & & & & \\
\hline & $\begin{array}{l}\text { 5) Apoio a equipe para obter } \\
\text { resultados de excelência }\end{array}$ & & & & & & & & & & & & & & & \\
\hline & 6) Feedback & \multirow{2}{*}{ 3) Incentivo } & & & & & & & & & & & & & & \\
\hline & 7) Motivação & & & & & & & & & & & & & & & \\
\hline & 8) Participação dos pais & \multirow{2}{*}{ 4) Rede de apoio } & & & & & & & & & & & & & & \\
\hline & 9) Parcerias & & & & & & & & & & & & & & & \\
\hline \multirow{6}{*}{ 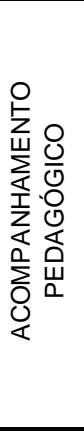 } & $\begin{array}{l}\text { 10) Processo de enturmação } \\
\text { heterogênea }\end{array}$ & \multirow{5}{*}{$\begin{array}{l}\text { 5) Acompanhamento do } \\
\text { professor }\end{array}$} & & & & & & & & & & & & & & \\
\hline & 11) Currículo pré-planejado & & & & & & & & & & & & & & & \\
\hline & 12) Acompanhamento do currículo & & & & & & & & & & & & & & & \\
\hline & $\begin{array}{l}\text { 13) Acompanhamento do trabalho } \\
\text { do professor }\end{array}$ & & & & & & & & & & & & & & & \\
\hline & 14) Reuniões de Modulo II semanal & & & & & & & & & & & & & & & \\
\hline & 15) Monitoramento dos alunos & $\begin{array}{l}\text { 6) Monitoramento do } \\
\text { aprendizado }\end{array}$ & & & & & & & & & & & & & & \\
\hline \multirow{9}{*}{ 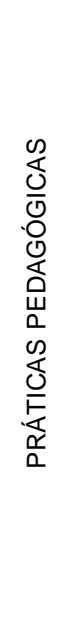 } & 16) Cumprimento do Currículo & \multirow{2}{*}{ 7) Planejeamento } & & & & & & & & & & & & & & \\
\hline & 17) Apoio a criação do BNCC & & & & & & & & & & & & & & & \\
\hline & 18) Recursos diversificados & \multirow{2}{*}{$\begin{array}{l}\text { 8) Execução de práticas } \\
\text { pedagógica }\end{array}$} & & & & & & & & & & & & & & \\
\hline & 19) Recurso do Dever de Casa & & & & & & & & & & & & & & & \\
\hline & \begin{tabular}{|l|} 
20) Alta expectativa de \\
aprendizagem dos alunos
\end{tabular} & $\begin{array}{l}\text { 9) Expectativas de } \\
\text { aprendizado }\end{array}$ & & & & & & & & & & & & & & \\
\hline & 21) Avaliação da aprendizagem & \multirow{4}{*}{$\begin{array}{l}\text { 10) Avaliação de } \\
\text { aprendizado }\end{array}$} & & & & & & & & & & & & & & \\
\hline & $\begin{array}{l}\text { 22) Preparação dos alunos para } \\
\text { Prova Brasil }\end{array}$ & & & & & & & & & & & & & & & \\
\hline & $\begin{array}{l}\text { 23) Sofre influência das avaliações } \\
\text { externas }\end{array}$ & & & & & & & & & & & & & & & \\
\hline & $\begin{array}{l}\text { 24) Ações para dificuldade de } \\
\text { aprendizagem }\end{array}$ & & & & & & & & & & & & & & & \\
\hline
\end{tabular}

Legenda: verde: respostas afirmativas. Vermelho: respostas negativas. Azul: quando o entrevistado não soube responder ou não falou sobre a categoria.

Fonte: autores. 
Pollyanna Silva de Paulo Faria é consultora educacional na Fundação de Desenvolvimento Gerencial.

Orcid: https://orcid.org/0000-0002-9768-2882.

Endereço: Rua Parus, 44 - 32240-130 - Contagem - MG - Brasil.

E-mail:pollydot@gmail.com.

Maria Teresa Gonzaga Alves é professora na Universidade Federal de Minas Gerais.

Orcid: http://orcid.org/0000-0001-5820-4311.

Endereço: Av. Antônio Carlos, 6627 - 31270-901 - Belo Horizonte - MG - Brasil.

E-mail: mtga@ufmg.br.

Recebido em 26 de fevereiro de 2020.

Aceito em 2 de maio de 2020.

(c) (i) 